\title{
The Fish-Tetrapod Transition: New Fossils and Interpretations
}

\author{
Jennifer A. Clack
}

Published online: 17 March 2009

(C) Springer Science + Business Media, LLC 2009

\begin{abstract}
Our information on the transition between fish with fins and tetrapods with limbs and digits has increased manyfold in the last 15-20 years and especially in the last 5 or 10 years, with some spectacular finds of new material. Some of these include new tetrapod-like fish and very primitive tetrapods that help to resolve questions of the sequence of acquisition of tetrapod characters, the approximate timing of the events, the likely geographic location, and the circumstances under which it happened. Forelimbs and skulls became modified in advance of hind limbs, adapted for supporting the head and front of the body out of the water, probably in connection with air breathing. The likely time of origin for limbed tetrapods is between 385 and 380 million years ago, probably in the northern continent of Laurussia. The origin of limbed tetrapods did not coincide with the acquisition of full terrestriality, an outcome that probably arose in the Early Carboniferous. This later part of the story is documented by few fossils, though two in particular give key information. Studies of modern vertebrates, especially the evolutionary developmental genetics of Hox genes, are beginning to provide clues to the origin of digits.
\end{abstract}

Keywords Late Devonian Panderichthys - Tiktaalik. Ventastega $\cdot$ Acanthostega $\cdot$ Tulerpeton Pederpes . Casineria

J. A. Clack $(\square)$

University Museum of Zoology,

Downing St.,

Cambridge CB2 3EJ, UK

e-mail: j.a.clack@zoo.cam.ac.uk

\section{Introduction}

The idea that, once upon a time, creatures with fins left the water and crawled up onto the land is one that has pretty wide currency among the general public. It is recognized in many a cartoon, as well as being referred to in some form in a wide variety of media, and is often featured in books on prehistoric animals. However, the details are often only vaguely understood and often originate in ideas about the subject that were put forward in the early years of the twentieth century, based on very little in the way of hard facts. It was thus possible to misrepresent or lampoon scientific views of the subject, since speculation seemed to be in inverse proportion to the amount of data. In recent years, especially in the last 5 or 10 years, information and ideas about "the fish-tetrapod transition" have expanded and changed enormously, so that we can now refer to a wealth of fossil and other evidence to generate plausible and testable hypotheses.

In a nutshell, the "fish-tetrapod transition" usually refers to the origin, from their fishy ancestors, of creatures with four legs bearing digits (fingers and toes), and with joints that permit the animals to walk on land. This event took place between about 385 and 360 million years ago toward the end of the period of time known as the Devonian. The Devonian is often referred to as the "Age of Fishes," as fish form the bulk of the vertebrate fossil record for this time.

Today, the term tetrapod includes all those animals that have legs, as well as those whose ancestors had them but which have since abandoned or modified them, such as whales and bats (these are mammals like ourselves), snakes (whose immediate relatives are lizards), birds (which are descended from dinosaurs), and frogs (amphibians represent a separate group of tetrapods from the amniotes, the group that includes all the others): They all share a common 
ancestor that had legs and which lived some time between the late part of the Devonian and the early part of the Carboniferous (Mississippian), the succeeding geological period.

\section{Early Ideas About the Fish-Tetrapod Transition}

In the past, this event was represented by only two or three fossil animals that spanned the great divide between fish with fins and tetrapods with limbs. On the "fish" side of the divide sat Eusthenopteron. This fish, from the early part of the Late Devonian, found mainly in Canada, is often shown crawling across a dry landscape using its forefins to move around (Figs. 1 and 2). On the "tetrapod" side was Ichthyostega, from later in the Devonian, found in Greenland. This was the first Devonian tetrapod ever found, in the 1930s, and became the icon for the first tetrapod, often called the "four-legged fish" (Figs. 1 and 3). Another fossil tetrapod also played a part. Eryops was a creature from the Permian period, about
290 million years ago, common in Texas red-beds deposits, and in the early decades of the twentieth century was one of the few early tetrapods known from good skeletal remains (Fig. 4). Many scenarios and hypothetical intermediates were drawn from its anatomy. A background to this general area and to some of these scenarios can be found in Clack (2002a).

As we now understand it, Eryops is rather an unusual creature and does not represent a primitive tetrapod in any respect. It is a relatively late member of a group of tetrapods whose origins can be traced back about 45 million years before Eryops appeared. Ichthyostega, far from being representative of a Devonian tetrapod, turns out to be highly specialized in its own way. Because it did not fit preconceptions of a primitive tetrapod and because remains of Eryops were more abundant, more complete, and more accessible to the researchers, Ichthyostega hardly contributed anything to the debate during the twentieth century, and instead, Eryops was more often used in anatomical speculations.

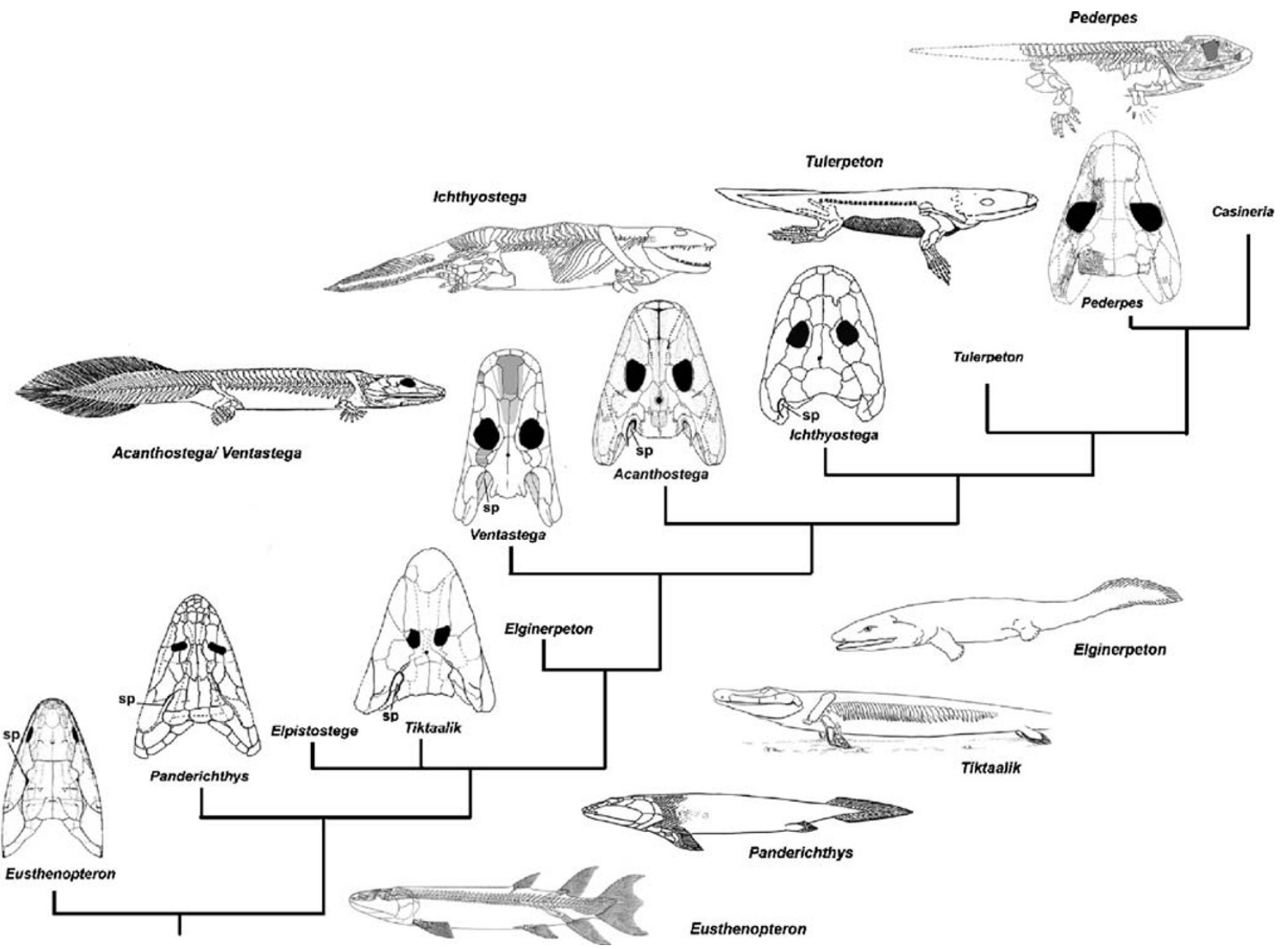

Fig. 1 Cladogram showing relationships of tetrapodomorphs according to a current consensus. Skulls and skeletal or body reconstructions are shown where these are available. Drawings are not to scale 


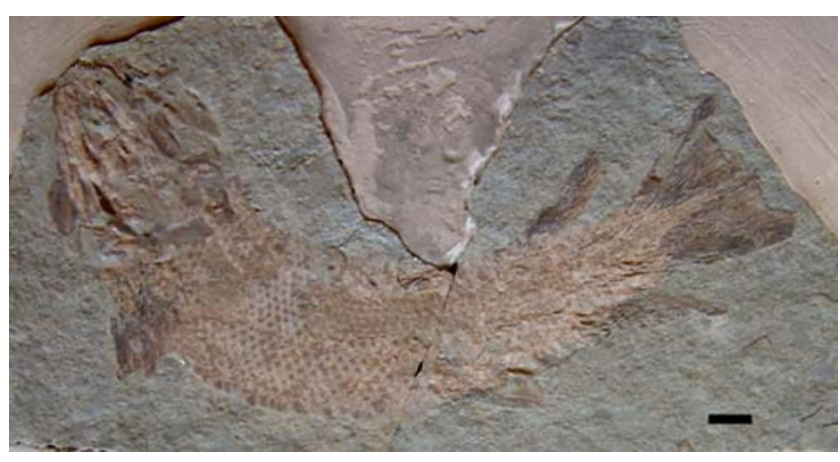

Fig. 2 Eusthenopteron foordi. University Museum of Zoology Cambridge specimen GN.786. Scale bar is 10 millimeters. Photograph by JAC

\section{Emerging Ideas}

Today, following a period of nearly 20 years during which the subject has undergone a renaissance, we have a much enriched fossil record on which to draw. Much of this recent work has yet to be reflected in popular accounts of the subject and, in some cases, even in biology textbooks.

Devonian tetrapods and their closest fish relatives are now known from worldwide localities, and though still rare, the new cast of characters gives us enough information on which to base ideas: The sequence of acquisition of tetrapod-like characters, the sorts of environments in which they lived, and the timing of the events leading to the origin of tetrapods have all become approachable using the fossil record, and some questions are even becoming answerable by use of developmental and genetic studies of modern animals. See also Clack $(2005,2006)$ for further information about some of the more recent developments.

One of the first points to assimilate in understanding the new story of the origin of tetrapods is that of phylogenythe way in which the animals in question are related to one another. Understanding this evolutionary relationship allows for testable hypotheses about, for example, the order in which tetrapod-like characters appeared. That can suggest hypotheses of how or for what reason these characters arose. There is now a good consensus in the paleontological community over the relationships of the taxa that represent the transition, though, of course, this remains and will always remain provisional. Figure 1 shows the current consensus of the relationships of the animals referred to in this piece (Ahlberg et al. 2008).

Tetrapods as a group belong to the lobe-finned vertebrates, whose only other modern representatives are the coelacanth and the lungfishes. These all had a common
Fig. 3 Ichthyostega spp.

Top, Ichthyostega stensioei, Geological Museum Copenhagen (MGUH) VP 6115, shown assembled with the rear of the skull, left shoulder girdle, and forearm and trunk ribs. Outline of anterior of skull restored according to Ahlberg et al (2005). Lower left, Ichthyostega watsoni, skull restoration from a latex peel of the natural mould of specimen MGUH VP 6064. No scale bar, skull about 200 millimeters long. Lower right, I. stensioei, superimposition of part and counterpart of specimen MGUH fn. 1349, right hind limb. Stippled line shows approximate line of division between part and counterpart. Scale bars are 10 millimeters
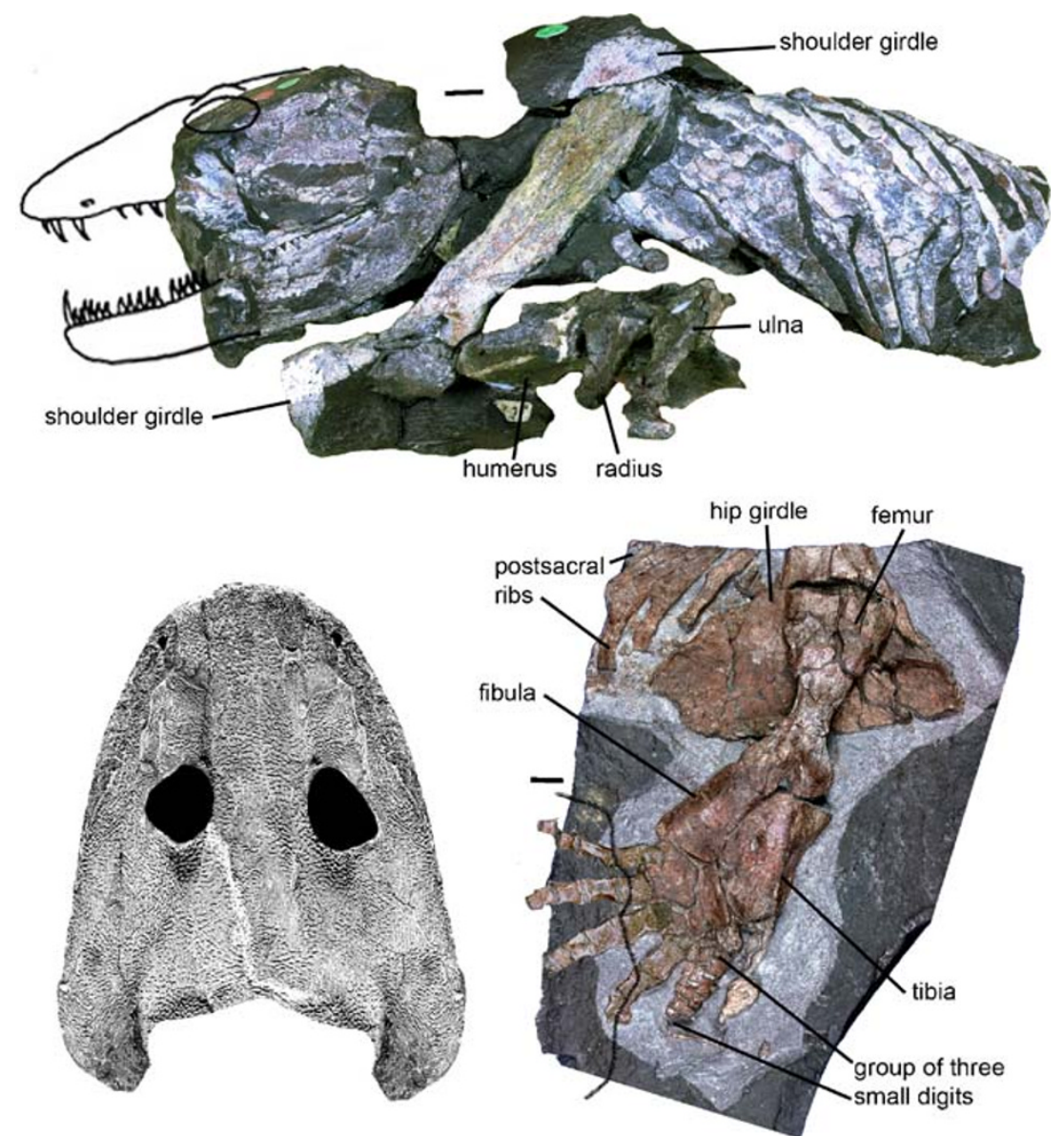


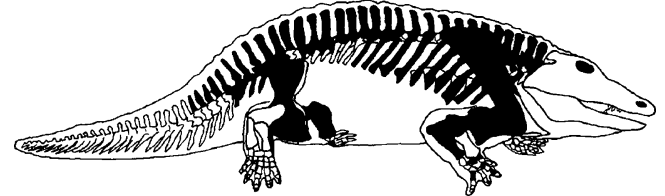

Fig. 4 Eryops megacephalus. Skeletal restoration showing restored body outline. Infilled regions show postcranial elements restored from a single specimen. Based on a skeletal model in the University Museum of Zoology, Cambridge, about 1.5 meters long

ancestor in the Early Devonian, meaning that, although they are related, these three groups are all very specialized in their own ways. Most modern evidence suggests that lungfishes are more closely related to tetrapods than are coelacanths, despite earlier conceptions of the coelacanth as an iconic "tetrapod ancestor." Lobe-fins are quite distinct from the ray-finned fishes, the group to which almost all modern fish belong. The lobe-fins have in common the arrangement of bones in the fin or limb skeleton: One bone is attached to the shoulder or hip girdle, equivalent to the humerus and femur. For understanding the origin of tetrapods, it is necessary to look at closer relatives, now only found in the fossil record. The group that includes them is called the tetrapodomorphs, the earliest known member of which is mid-Devonian. In tetrapodomorphs, two bones attached to the humerus and femur, equivalent to the radius/ulna and tibia/fibula (Fig. 5). Eusthenopteron is a tetrapodomorph from the early part of the Late Devonian.

\section{Our Cast of Characters: Old and New Material}

Eusthenopteron belongs to a family called the tristichopterids, though it is not the most primitive member of this family. Thus, it is necessary to check whether any feature cited as representing the transition was really present in more primitive members, or whether Eusthenopteron has developed it in parallel with tetrapods. This is a general principle when trying to work out evolutionary transitions.

Eusthenopteron grew up to a meter long. Its fin skeleton, with a substantial humerus, radius, and ulna as well as other robust skeletal elements, has provided the baseline from which to evolve a limb. It has been known since the early twentieth century, when it provided the basis for many transformation scenarios.

A feature shared by most fishes is the bone called the hyomandibula that supports the palate and controls movements of the gill apparatus. It is a long bone that pivots on the walls of the bone housing the brain and ear capsules, the braincase, and it has attachment points to the gill bars and the opercular series, the plate-like bones that cover and protect the gills. They are all part of the pumping mechanism used in breathing and feeding. Eusthenopteron was entirely typical of early fish in this respect.

In 1938, parts of the skull of a fossil fish were found in the same deposits as Eusthenopteron. Although only known from a partial skull roof, its proportions seemed more like those of a tetrapod than a fish (Westoll 1938). It was named Elpistostege, and it remained a tantalizing and intriguing puzzle for many decades, even though additional material in the 1980s added more information and corroborated Westoll's view (Schultze and Arsenault 1985). Elpistostege is now recognized as closely related to the next two players in the story.

More recently, two such fish have been increasingly under the spotlight as being more closely related to tetrapods and having more transitional characters. The first is called Panderichthys, and though it has been known from reasonably complete specimens since the 1970s, many of its key features are only just being described. It comes from the Late Devonian of the Baltic states and Russia, and it is approximately contemporary with Eusthenopteron, even possibly a little earlier. It grew to well over a meter in length (Figs. 1 and 6). Its tetrapod-like features include loss of all its midline fins - dorsal and anal-a flatter skull, a much longer snout, and larger and more dorsally place eye sockets than Eusthenopteron (Vorobyeva and Schultze 1991). Its humerus and shoulder girdle are relatively larger and show more tetrapod-like morphology than those of Eusthenopteron, for example in having larger areas for muscle attachment (Vorobyeva 1995, 2000). Recently, it has been shown that its spiracular cleft is larger than that in
Fig. 5 Left forelimbs of modern coelacanth, Latimeria, the lungfish Neoceratodus, and fossil tetrapodomorphs in dorsal view (not to scale). Panderichthys fin skeleton based on CT reconstruction in Boisvert et al. (2008)
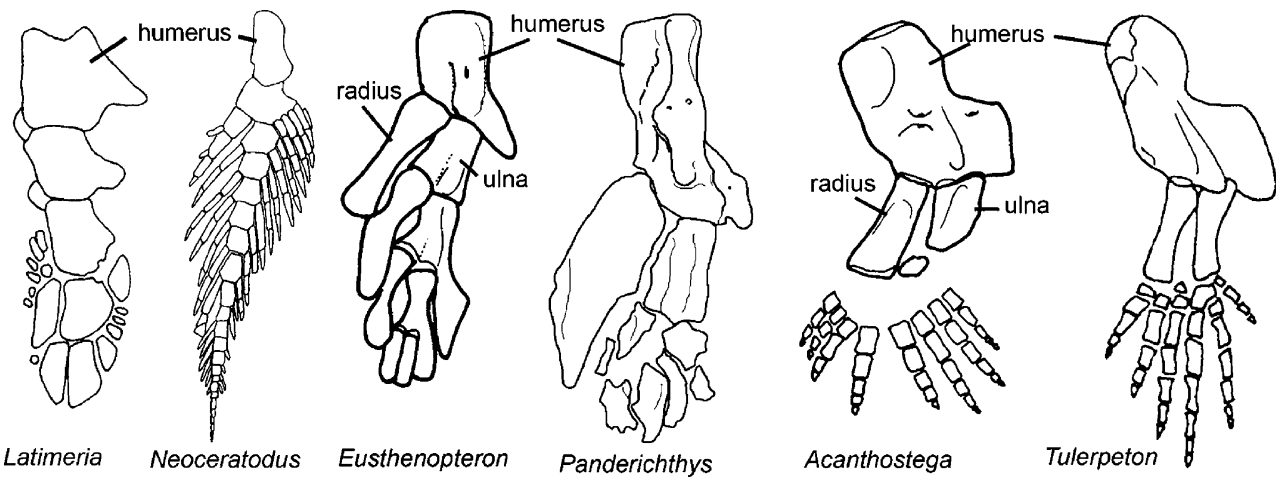


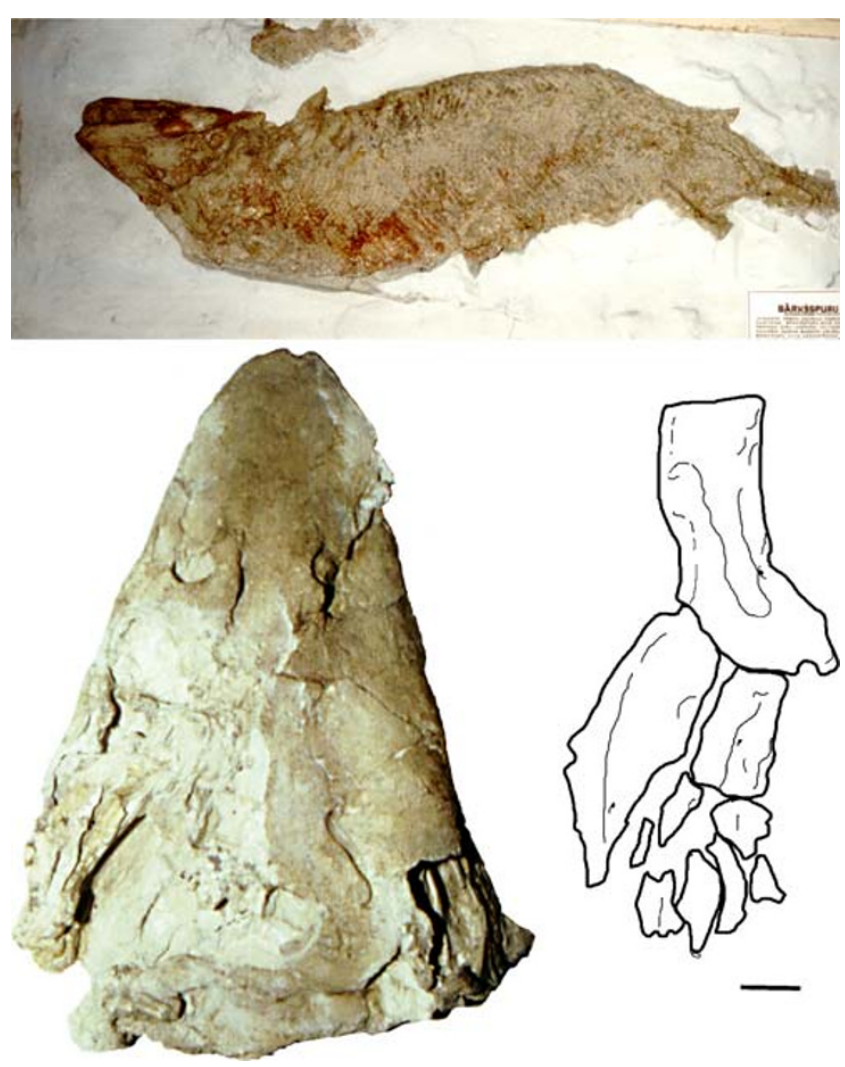

Fig. 6 Panderichthys rhombolepis. Top, specimen in the Latvian Natural History Museum, Riga. Photograph by P. E. Ahlberg. Specimen is approximately 1 meter long and is preserved in oblique ventral view. Lower left, skull in dorsal view, about 300 millimeters long. Photograph by JAC. Lower right, elements of right pectoral fin in ventral view, based on CT reconstruction in Boisvert et al. (2008)

Eusthenopteron and approaches that of an early tetrapod in size and shape. The spiracle may have been open to the outside, a feature that has been associated with air breathing. The ossified portion of the hyomandibula is much shorter than in Eusthenopteron, although it still contacted the opercular bones (Brazeau and Ahlberg 2006). Based on the interpretation of computed tomography scans of a relatively uncrushed specimen, it has been further shown that its fin skeleton possesses the most tetrapod-like features of any fish (Boisvert et al. 2008; Figs. 1 and 6).

In the last couple of years, a second, in some ways even more tetrapod-like fish, has been discovered. This is Tiktaalik, from the Late Devonian of Canada. A joint team from the Universities of Chicago and Harvard and the Academy of Natural Sciences in Pennsylvania targeted a locality on Ellesmere Island in northern Canada because a geological survey showed rocks of the right age and environmental setting to yield fossils representing the fish-tetrapod transition. For several years, they found nothing much, but eventually their predictions paid off and their efforts were rewarded with magnificent specimens of a new tetrapod-like fish (Daeschler et al. 2006; Figs. 1 and 7).
Tiktaalik is known from several almost complete specimens, preserved in three dimensions. It shows many typical fish-like features such as scales, in its case bony and rhomboidal in shape. Its head, which grew to over 300 millimeters long, shows some similar features to Panderichthys, but is even more tetrapod-like: It has an even longer snout and even larger eyes. Furthermore, the shoulder girdle appears not to contact the back of the head as it does in fish including Panderichthys. In some ways, it is even more similar to Elpistostege. Crucially, however, because of its excellent preservation, some key features were shown. In other fish, including Eusthenopteron and Panderichthys, as well as the opercular bones that cover the gill region, another series joins the head to the shoulder girdle. In Tiktaalik, the operculars and some of the shoulder series were no longer present. The hyomandibula is shorter again than in Panderichthys, suggesting the onset of changes to the gill region and to the fish's breathing mechanism compared with conventional fish. Detachment of the head from the shoulder girdle implied that the head was more mobile and could have been raised and lowered further and more easily than in other fish. On top of the head, the opening to the spiracular chamber is broad and rounded (Daeschler et al. 2006).

One important aspect of Tiktaalik's fin structure is that because of the excellent preservation, the bones of the fin skeleton could be removed from the surrounding rock and actually manipulated against one another to investigate their range of movement. The team describing this movement suggested that it showed a joint construction that foreshadowed that of a tetrapod wrist and that it could be used in support of the front end of the body. Whether this was done with the body in or out of water is not certain, but it would certainly be reckoned as a forerunner of a supportive limb

Fig. 7 Tiktaalik roseae. Photograph of one of the most complete specimens, Nunavut Fossil Vertebrate Collection (NUFV 108). Photograph by JAC

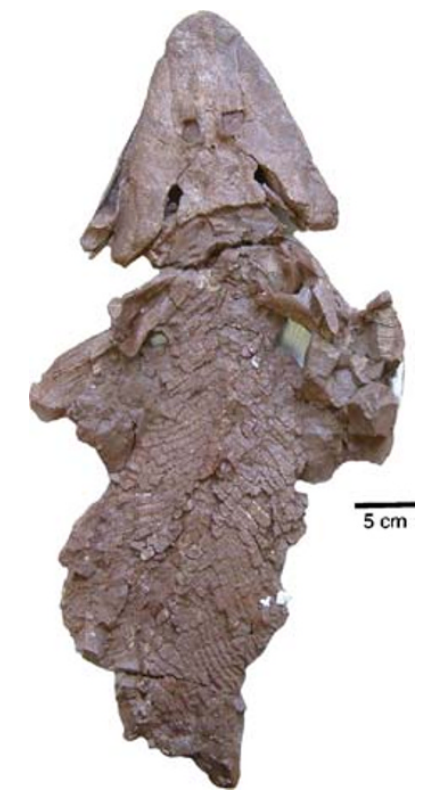


(Shubin et al. 2006). Supporting the notion that Tiktaalik was raising the front end of the body, it has broad overlapping ribs running down the length of the trunk to form a strengthening "corset." At the same time, the paired fins of Tiktaalik still retain fin rays: Loss of fin rays is part of the way in which limbs are distinguished from fins. By that criterion, Tiktaalik is still a fish: It has fins as well as scales, but its overall construction helps to blur the conventional boundary between "fish" and "tetrapod."

Tiktaalik, Panderichthys, and Eusthenopteron show very similar construction in the lower jaw and in the arrangement of teeth in those jaws, suggesting that they fed in similar ways (Daeschler et al. 2006). It turns out that early tetrapods can be recognized because they show new features of the dentition and jaw construction, so that tetrapods can be identified just from their lower jaws (Ahlberg and Clack 1998). The implication is that tetrapods had begun to diverge away from a fish-like feeding technique. Since they also differ between taxa, they had begun to diversify into different niches.

One of the first tetrapod fossils to be recognized in this way was Elginerpeton, first identified from some fragments of skull and lower jaw in the University Museum in Oxford. The elements come from Scat Craig, near Elgin in Scotland and date from the early part of the Late Devonian (Ahlberg 1991). As well as jaw fragments, the fossils include tetrapod-like girdle elements. Thus, Elginerpeton is the earliest animal known to have had limbs. They also indicate the existence of a rather large animal (Fig. 1), as the skull is considered to be about 400 millimeters long (Ahlberg 1995, 1998).

Another Devonian tetrapod first recognized from a lower jaw is Ventastega. Initially interpreted as belonging to a panderichthyid, it was eventually recognized as a tetrapod on the basis of lower jaw and girdle material collected by Russian and Lativan paleontologists. Further expeditions to the site have yielded spectacular material. This site, from the late part of the Late Devonian, is on a river bank, and the fossils occur in almost unconsolidated sand. They require little excavation, though the bones need to be consolidated with resins before they can be studied (Ahlberg et al. 1994).

Remains from this site now include, in addition to many lower jaws, an almost complete skull, along with some shoulder and hip girdle elements that closely resemble those of another Devonian tetrapod, Acanthostega (see below; Figs. 1 and 8). From this, it is inferred that Ventastega had limbs with digits. The skull of Ventastega falls in appearance almost exactly intermediate between Tiktaalik and Acanthostega: The differences are largely those of proportion. It has relatively larger eyes and a longer snout, and the portion of the skull behind the eye sockets is relatively shorter than in Tiktaalik. In the region
Fig. 8 Ventastega curonica. Photograph of the most complete skull in dorsal view, gray areas show partially restored skull outline. Latvian Natural History Museum specimen LDM G81/775. Scale bar 10 millimeters. Photograph courtesy of E. Luksevics

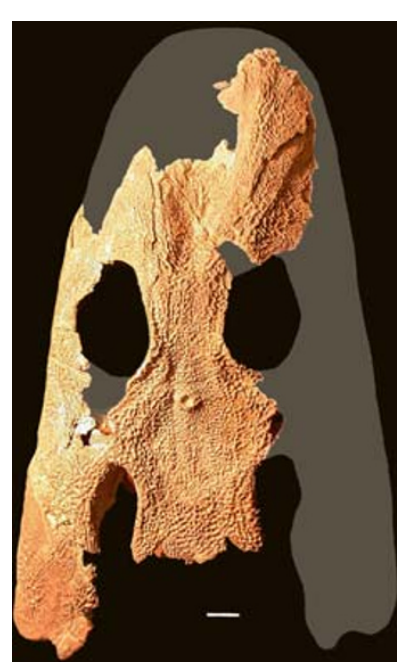

of the snout in which fish such as Eusthenopteron and Panderichthys have a mosaic of small bones, Ventastega actually has a gap running along the midline of the skull, suggesting that this might be a stage in losing that mosaic. However, the opening of the spiracular cleft and some details of the back of the skull are virtually identical between Ventastega and Tiktaalik. Ventastega also shows a mixture of fish-like and tetrapod-like characters in the braincase. Some of the most profound changes that took place during the fish-tetrapod transition affected this region of skull anatomy (Ahlberg et al. 2008).

The differences between fish such as Eusthenopteron and Panderichthys and tetrapods such as Acanthostega in the bones of the braincase and ear region have been considered as representing a sudden and complex change as compared with those to the skull, which have been seen as gradual. Although the braincase changes may be have been relatively rapid, information from Ventastega tends to suggest that they nevertheless took place by a series of small changes, rather than one extreme change (Ahlberg et al. 2008).

It was the discovery and description of Acanthostega in the 1990s that really initiated the revival of studies and thinking about the fish-tetrapod transition. It came from the same localities as Ichthyostega in Greenland, and the two were contemporary. However, renewed collecting in Greenland in 1987 found almost complete skeletons of Acanthostega that changed perceptions of what a Devonian tetrapod was like (Figs. 1 and 9). Acanthostega was preserved in hard rock, and the fossil bones had to be dug out very slowly and carefully in a process that took several years to complete. This done, whereas Ichthyostega had proved somewhat of an anomaly, Acanthostega proved to be more or less exactly what an early tetrapod "ought" to be like. It retained a number of fish-like features, but was nevertheless a tetrapod by the definition of having limbs with digits.

The fish-like features of Acanthostega include a tail fin supported by long bony rays, to make an oar shape. Fin 


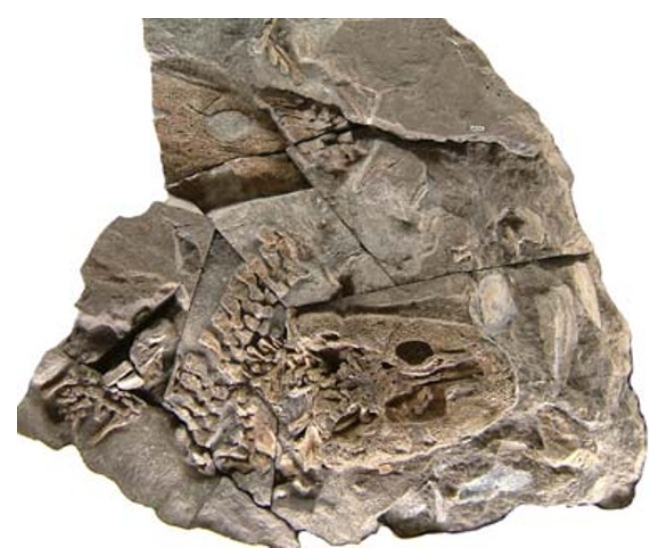

Fig. 9 Acanthostega gunnari. Photograph of one of the most complete skeletons, MGUH fn. 1227. Left forelimb is to the left, and a second skull to the top right of the specimen. Skull of main specimen about 120 millimeters long. Photograph by JAC

rays had been found in the tail of Ichthyostega, but they were much shorter and less numerous. The ribs of Acanthostega are short and slender and much the same all down the length of its body (Coates 1996; Fig. 1). Ichthyostega was known to have had broad overlapping ribs at least in its trunk region. In the skull, Acanthostega has a slot running down the midline of the snout, similar to the gap found there in Ventastega (Clack 2003). Acanthostega also retains a set of well-ossified grooved gill bars, suggesting that these were still actively involved in gill breathing, though it probably breathed air by gulping as well (Coates and Clack 1991).

In other respects, Acanthostega showed some typical tetrapod features. It has a robust pelvic girdle and a large femur. It is the pelvic region and the hind limb that most conspicuously distinguish a fish from a tetrapod, and that distinction is still valid among modern animals. In fish, the pelvic girdle is usually small and not attached to the vertebral column and the pelvic fin is diminutive, whereas in tetrapods, the pelvic girdle is large, attached to the vertebral column and bears the substantial hind limbs that provide most of the propulsive power in walking. In Acanthostega, although the pelvic girdle is enlarged, it is still relatively small compared with later tetrapods and was only attached to the column by soft tissue rather than a bony junction (Coates 1996).

The humerus bears close comparison with those of Panderichthys and Tiktaalik, and most of the muscle attachment points and other features can be recognized as similar between them. In that of Acanthostega, however, they are much further elaborated, suggesting larger and more differentiated musculature. The radius and ulna as well as the tibia and fibula attach at the extreme ends of their respective humerus and femur. Combined with the more or less horizontal orientation of the forearm, this suggests that the elbow and knee joints were relatively weak and did not form an effective supporting limb, at least not for walking on land. That arrangement fits with other information about the limbs that constitutes the most unexpected aspect of Acanthostega (Coates 1996).

Some excellent specimens showed that it had eight digits on the forearm (Figs. 5 and 9) and almost certainly eight (or maybe more) on the hind limb. That they are so neatly laid out in the fossil may be because they were enveloped in a web of skin. The wrist bones were not ossified, but it is clear that the digits were arranged in a broad arc around where those bones would have been, but the result would not have made a flexible or supportive wrist. The limb was in effect a paddle (Coates and Clack 1990). Similarly, although the ankle bones are well ossified, they do not show an obvious joint surface along which the limb could bend. Again, the limb seems to have been a paddle. From that evidence, it was suggested that limbs with digits first evolved not for walking on land but for swimming or wading through water (Coates and Clack 1995).

In the braincase and ear region, Acanthostega showed features in which it was distinctively more tetrapod-like than fish-like. In tetrapods, rather than a hyomandibula pivoting on the braincase wall, essentially the same bone but now termed the stapes, fits into a hole in the braincase wall called the fenestra vestibuli or fenestra ovalis. Acanthostega shows this pattern in a very early form (Clack 1989, 1994). The arrangement later became modified into the combination of a stapes and a fenestra ovalis that is characteristic of all tetrapods and is still part of the hearing mechanism in humans.

If Acanthostega is a mixture of fish-like and tetrapodlike characters, Ichthyostega is a mixture of apparently aquatic specializations with others that appear more modified for land excursions. Recent study has revealed a rather different animal from the old image of an overlarge salamander-like body form.

One of the parts of the anatomy that had puzzled earlier workers was the ear region. Using newly collected and prepared fossil material, together with microcomputed tomography scanning of key fossils, the unique arrangement found in Ichthyostega has been interpreted as a highly specialized underwater auditory organ (Clack et al. 2003). By contrast, work on its postcranial skeleton has suggested that it may have had a unique form of locomotion on land. The vertebral column is differentiated into separate regions, including a lumbar portion that seems to have accommodated dorsoventral flexion (Ahlberg et al. 2005). The shoulder girdle and forearm are large and robust, suggesting extensive musculature, perhaps for pulling the animal along on land. Its hind limb is quite similar in construction to that of Acanthostega, that is to say a paddle with no obvious ankle joint, and it has seven toes arranged in a unique 
pattern (Coates and Clack 1990). A group of three small toes form a strengthening bar along the leading edge, with four stouter ones behind (Figs. 1 and 3). It is likely that, as in Acanthostega, these were contained in a web of skin. The hind limb may have given stability and purchase on the substrate and been used as a flipper in water, but it was not a conventional walking leg. It is no surprise that this peculiar morphology caused problems for early workers trying to understand Devonian tetrapods. It shows that even by that time, tetrapods had diversified into a wider range of morphologies than was previously appreciated.

Analysis of all the skull specimens of Ichthyostega has shown changes to proportions and skull bone ornamentation that varies throughout its history and that document microevolution at the specific level in these very early tetrapods. Skulls from lower formations are narrower, with finer ornament, than those from higher up in the geological sequence (Blom 2005).

Two other localities have yielded Devonian tetrapod remains that consist of more than lower jaw fragments and give evidence of further diversity and geographical distribution. The third Devonian tetrapod to be identified, in the mid-1980s, came from Russia. It consists of a partially articulated skeleton and is called Tulerpeton (Lebedev 1984). The limbs are well preserved and show long bones that are more slender and more like those of later tetrapods than either Acanthostega or Ichthyostega, suggesting at first sight a more terrestrial animal. However, Tulerpeton has six toes on the forelimb (Fig. 5) and almost certainly six on the hind; its wrist and ankle bones are not easily comparable with those of later tetrapods; and it was found in the environmental setting of a shallow marine sea (Lebedev and Clack 1993; Lebedev and Coates 1995). This was the first hint that the earliest tetrapods were not necessarily purely freshwater animals and that they did not have the conventional number of five toes. Both conclusions, surprising at the time, have been confirmed since by other finds.

A road cut near Hyner in Pennsylvania, called Red Hill, has given us a number of Late Devonian tetrapod elements. The environment it shows was a river flood plain with a monsoonal climate, and the site has yielded a great variety of plants, invertebrates, and fish, as well as tetrapods (Cressler 2006). The best-known tetrapods are two different lower jaws and two similar partial shoulder girdles (Daeschler 2000; Daeschler et al. 1994). The shoulder girdles show some similar features to those of Acanthostega but suggest that the animal had a greater muscle mass. There is also an unusual isolated humerus that almost certainly does not belong to the shoulder girdles (Shubin et al. 2004). The jaws show that there were at least two kinds of tetrapod there, but further isolated bones have since been identified that imply the existence of three or four. One of these is a single bone from the snout of a tetrapod, the lacrimal bone.
Intriguingly, it resembles that of a later tetrapod, Pederpes, from the Early Carboniferous of Scotland (Daeschler et al. 2009).

The transition to fully terrestrial tetrapods did not end in the Devonian. It was a gradual process that continued into the Early Carboniferous, though the fossil record of post-Devonian tetrapods is notoriously sparse for about 30 million years after the Devonian/Carboniferous boundary. Pederpes is one of the few fossil animals known from that period (Clack 2002b; Clack and Finney 2005) (Figs. 1 and 10). This animal, belonging to a group known as the whatcheeriids, not only shows some primitive features in which it resembles the Devonian forms but also has more advanced features that suggest the beginnings of terrestriality. Its hind limb was fairly typical of a conventional tetrapod from the Late Carboniferous and appears to have had five digits. The foot appears to have pointed forward as in a terrestrially walking animal, rather than to the side as in Acanthostega. However, the forelimb may have had more than five digits, because the only two that are known are both extremely small and resemble the supernumeraries of Acanthostega and Ichthyostega. Pederpes has broad flanges on its ribs that resemble those of Ichthyostega in some ways. Its stapes is like that of Acanthostega.

The first indisputably fully terrestrial tetrapod known in the fossil record is Casineria from the Early Carboniferous of Scotland. It has a fully pentadactyl forelimb with a hand capable of flexing and with claw-like terminal elements and gracile limb bones (Paton et al. 1999; Fig. 11). This makes the point that the origin of tetrapods is not the same thing as the origin of terrestriality and walking.

\section{What Can We Learn from This Information?}

Our new array of tetrapod-like fish and fish-like tetrapods allows us to generate hypotheses about the events of the transition. Some of the most obvious changes occur in the skull and braincase. Our sequence of Eusthenopteron-

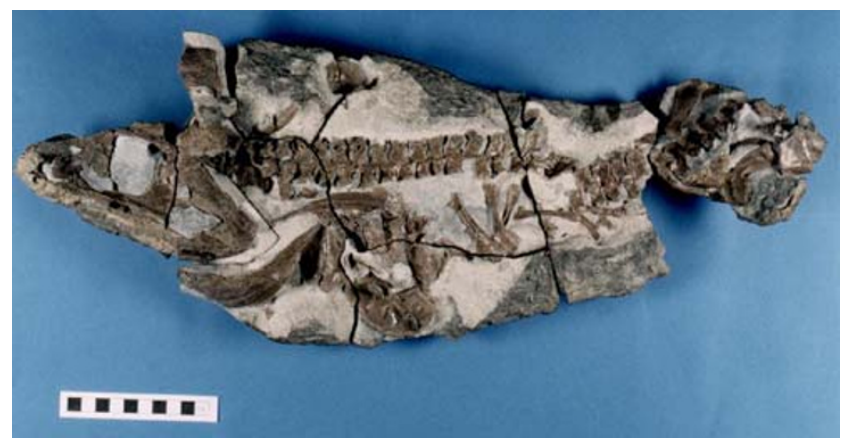

Fig. 10 Pederpes finneyae. Photograph of only specimen in left lateral view. Scale bar 10 centimeters. Photograph by S. M. Finney 


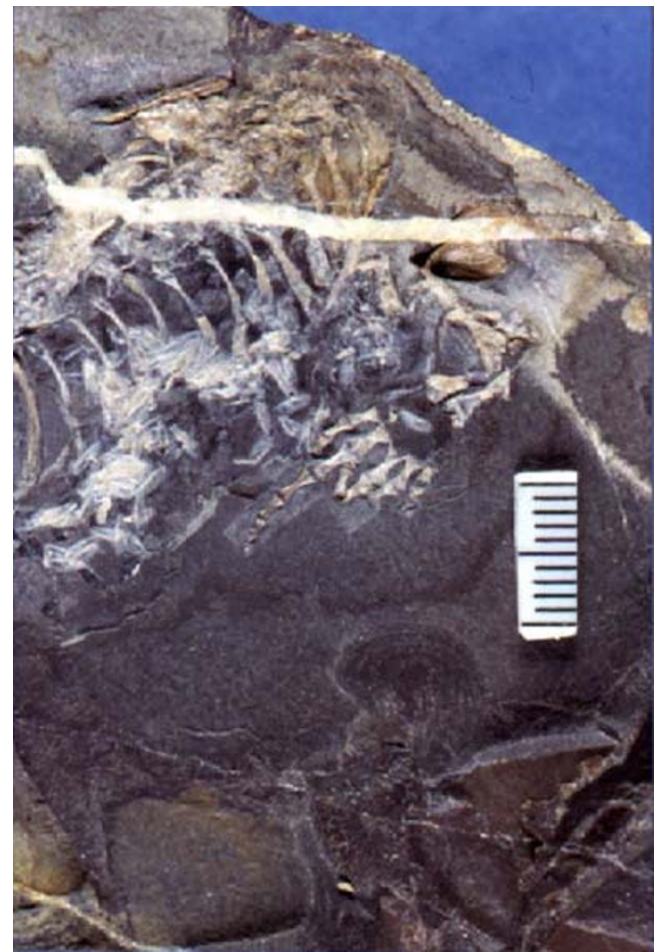

Fig. 11 Casineria kiddi. Photograph of counterpart of only specimen, showing ribs, gastralia, part of humerus, radius, ulna, and digits of forearm. Scale bar 10 millimeters. Photograph by S. M. Finney

Panderichthys-Tiktaalik-Acanthostega suggests that there are changes in proportion that occur quite gradually in the skull roof pattern. The snout elongates and the eyes enlarge and move dorsally, whereas the region behind the eyes, where the ear region is situated, reduces in length. It is not clear why this should be, though it may relate to changes in function of the balance organs, the semicircular canals, as the head is increasingly raised out of the water. The opercular bones decrease in length, shown by Panderichthys, and eventually disappear, at the same time as the hyomandibula reduces in length and the spiracular opening widens, all in concert (Clack 2005).

Changes to the shoulder girdle and forelimb take place at the same time. The humerus enlarges and gains more robust and prominent muscle attachment points, in keeping with becoming a more supportive appendage. It also changes its orientation from a more posterior-pointing appendage as it is in the fins of all three fishes above, to a more laterallypointing one. This is shown in the peculiar humerus from Red Hill and in Acanthostega and all other early tetrapods (Clack 2005). All of these changes could be associated with a move to reduce reliance on gill breathing in water to breathing air by gulping, with the forelimb being modified to raise the forequarters of the body out of the water. Changes to the hind limb seem initially to lag behind those to the forelimb. The hind limb in terrestrial tetrapods is the one that provides the thrust in walking, so that a lag in the development of the hind limb implies that the needs of walking on land were among the later skeletal changes to take place in the transition, rather than among the earliest, as early studies assumed (Coates et al. 2002).

Recent studies of the climatic, environmental, and atmospheric conditions in the Middle and Late Devonian have stimulated new scenarios about when and why tetrapods became air breathing. This period was a time of increasingly diverse plant cover on land, especially along water margins. Two bursts of evolution during the Middle and Late Devonian produced ever larger plants, so that by the end of the Devonian, full-scale forests covered the land. During the latter parts of this period, plants produced the first deciduous forms. All of this growth caused increased runoff of nutrients and decaying plant matter into the water, exploited by bacteria that used the dissolved oxygen to break down the debris. Layers of black shale in Devonian sequences are evidence of this, occurring worldwide. At the same time, other studies have shown that during this period the oxygen level in the atmosphere underwent a long-term decline to unprecedentedly low levels, reaching its nadir in the early Late Devonian. This combination of circumstances must have had profound effects on animal life in the water, and one consequence may have been to favor any forms that could exploit what oxygen there was in the air, as opposed to the even lower levels in the water (Clack 2007 and references therein).

Using the consensus phylogeny, we can now more closely pin down the timing of some of these events. The earliest member of the tetrapodomorphs are not known before the early mid-Devonian, with the tetrapod-like fishes

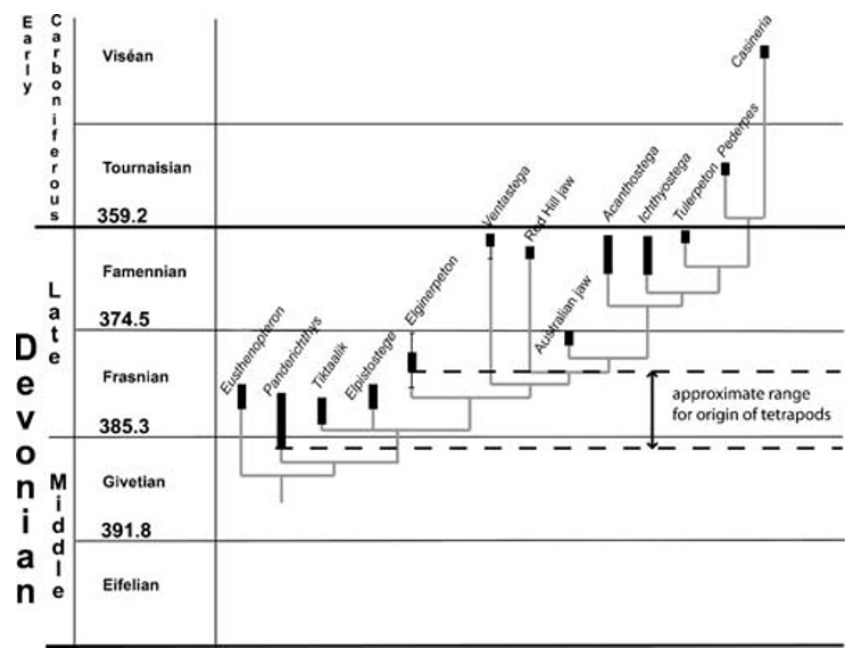

Fig. 12 Stratigraphic table of Late Devonian and Early Carboniferous with cladogram of tetrapodomorphs superimposed to show distribution in time. Broad bars show known range, narrow bars show possible range where exact dating is not available. Based on Ahlberg et al. (2008) 
Panderichthys and Elpistostege appearing in the latest part of the mid-Devonian, about 385 million years ago. Elginerpeton gives the latest date for the origin of limbs, around 380 million years ago. This gives a relatively short 5 million year window for the origin of limbed tetrapods in the early Late Devonian, though it could have been a bit earlier if it is assumed that Panderichthys and Elginerpeton were not actually the first of their kind (Fig. 12).

The geographical occurrence of Tiktaalik, Elpistostege, Panderichthys, and Elginerpeton in environments around the coast of the old continent of Laurussia that straddled the equator in the Late Devonian have led to the hypothesis that this was the region in which tetrapods probably originated (Daeschler et al. 2006). Most of the localities from which they derive are estuarine, although that is not known for Elginerpeton. This again suggests a brackish rather than a freshwater origin for the group as was assumed in the past and helps explain how, only a few million years later, Devonian tetrapods are found throughout the world. Jaw and other fragments have now been found in Australia (Campbell and Bell 1977, confirmed by Ahlberg and Clack 1998), China (Zhu et al. 2002), Belgium (Clement et al. 2004), and further sites in Russia (Lebedev 2004).

There are still many questions that remain unanswered. Additional fossils will probably be found to help answer them, but just as probably, research in developmental genetics may provide clues by examination of modern animals. The origin of digits, essentially strings of segmented elements developing in a sequence from the distal part of the limb, is a problem that developmental genetics is beginning to tackle. The action of sequences of genes called Hox genes are known to be implicated in the formation of digits. Certain Hox genes control the appearance and differentiation of digits in tetrapods. It is now known that these same genes control the formation of the fin skeleton in primitive modern fishes, so the implication is that rather than the occurrence of digits being a completely new phenomenon in tetrapods, in fact, tetrapods are reusing an old mechanism in a different way (Davis et al. 2007). The action of these same genes is being studied in the tetrapods' nearest living relatives, the lungfish, and are giving some hints about how fin skeletons and digits may be formed (Johanson et al. 2007).

The origin of the enlarged pelvis and hind limb is another question that may in future be approached by developmental genetics, though at present it remains understudied. Developmental genetics has tended to concentrate on the forefins and limbs of the animals studied and has assumed that the hind limbs would be similar. Fossils seem to suggest that this may not be the case (Coates et al. 2002). Unfortunately, no pelvic region of Tiktaalik has yet been found sufficiently well preserved to give useful clues to this important question, though the pelvic fin of Panderichthys has been described: It is much smaller than the pectoral fin and shows no obviously tetrapod-like features (Boisvert 2005).

This account of the origin of tetrapods has explicitly used a definition of tetrapods based on the possession of limbs with digits. However, with increasing knowledge of transitional fossil forms, increasing consensus over their relationships, and with progress in studies of the developmental processes underlying the formation of digits, it becomes increasingly difficult to define what constitutes either a digit or indeed a tetrapod. There are other ways of defining the group that produce a different answer to the question "when did tetrapods evolve?" and that is important when trying to calibrate timescales based on molecular evolution. Modern tetrapods, that is, amphibians and amniotes, had a common origin, and together are known as the Crown Group Tetrapoda. Fossil forms that do not fall within the crown group, but which are more closely related to them than they are to lungfishes, are known as stem group tetrapods, or sometimes, limbed tetrapodomorphs. The origin of the crown group is the only date that can be estimated using molecular data. It is unlikely to coincide with the origin of limbs with digits and more probably can be dated to some time in the Early Carboniferous, perhaps around the time of Casineria, though uncertainties in phylogeny makes this insecure. Tetrapodomorphs as a group have their origin in the Late Silurian or Early Devonian.

In summary, we now have a much richer fossil record that has improved our understanding of the timing, sequence of events, and conditions in which the origin of tetrapods took place. The boundary between "fish" and "tetrapods" is becoming progressively more difficult to draw, and a more complex story is emerging in which, for example, the origin of limbs with digits, the origin of walking and terrestriality, and the origin of tetrapods in a strict sense, may be three different things.

\section{References}

Ahlberg PE. Tetrapod or near tetrapod fossils from the Upper Devonian of Scotland. Nature 1991;354:298-301. doi:10.1038/354298a0.

Ahlberg PE. Elginerpeton pancheni and the earliest tetrapod clade. Nature 1995;373:420-5. doi:10.1038/373420a0.

Ahlberg PE. Postcranial stem tetrapod remains from the Devonian of Scat Craig, Morayshire, Scotland. Zool J Linn Soc. 1998;122:99141. doi:10.1111/j.1096-3642.1998.tb02526.x.

Ahlberg PE, Clack JA. Lower jaws, lower tetrapods - a review based on the Devonian genus Acanthostega. Trans R Soc Edinb Earth Sci. 1998;89:11-46.

Ahlberg PE, Luksevics E, Lebedev OA. The first tetrapod finds from the Devonian (Upper Famennian) of Latvia. Philos Trans R Soc Lond B Biol Sci. 1994;343:303-28. doi:10.1098/rstb. 1994.0027.

Ahlberg PE, Clack JA, Blom H. The axial skeleton of the Devonian tetrapod Ichthyostega. Nature 2005;437:137-40. doi:10.1038/ nature 03893 . 
Ahlberg PE, Clack JA, Luksevics E, Blom H, Zupins I. Ventastega curonica and the origin of tetrapod morphology. Nature 2008;453:1199-204. doi:10.1038/nature06991.

Blom H. Taxonomic revision of the Late Devonian tetrapod Ichthyostega from Greenland. Palaeontology 2005;48:111-34. doi:10.1111/j.1475-4983.2004.00435.x.

Boisvert C. The pelvic fin and girdle of Panderichthys and the origin of tetrapod locomotion. Nature 2005;438:1145-7. doi:10.1038/ nature 04119.

Boisvert CA, Mark-Kurik E, Ahlberg PE. The pectoral fin of Panderichthys and the origin of digits. Nature 2008;456:636-8. doi:10.1038/nature07339.

Brazeau M, Ahlberg PE. Tetrapod-like middle ear architecture in a Devonian fish. Nature 2006;439:318-21. doi:10.1038/nature04196.

Campbell KSW, Bell MW. A primitive amphibian from the Late Devonian of New South Wales. Alcheringa 1977;1:369-81. doi:10.1080/03115517708527771.

Clack JA. Discovery of the earliest-known tetrapod stapes. Nature 1989;342:425-7. doi:10.1038/342425a0.

Clack JA. Earliest known tetrapod braincase and the evolution of the stapes and fenestra ovalis. Nature 1994;369:392-4. doi:10.1038/369392a0.

Clack JA. Gaining ground: the origin and early evolution of tetrapods. Bloomington: Indiana University Press; 2002a. p. 369.

Clack JA. An early tetrapod from Romer's Gap. Nature 2002b;418:72-6. doi:10.1038/nature00824.

Clack JA. A revised reconstruction of fhe dermal skull roof of Acanthostega, an early tetrapod from the Late Devonian. Trans R Soc Edinb. 2003;93:163-5.

Clack JA. Making headway and finding a foothold: tetrapods come ashore. In: Briggs DEG, editor. Evolving form and function: fossils and development. Peabody Museum of Natural History special publications. New Haven: Yale University Press; 2005. p. 233-44.

Clack JA. The emergence of early tetrapods. Palaeogeogr Palaeoclimatol Palaeoecol. 2006;232:167-89. doi:10.1016/j.palaeo.2005.07.019.

Clack JA. Devonian climate change, breathing, and the origin of the tetrapod stem group. Integr Comp Biol. 2007;47:510-23. doi:10.1093/icb/icm055.

Clack JA, Finney SM. Pederpes finneyae, an articulated tetrapod from the Tournaisian of western Scotland. J Syst Palaeontology. 2005;2:311-46. doi:10.1017/S1477201904001506.

Clack JA, Ahlberg PE, Finney SM, Dominguez Alonso P, Robinson J, Ketcham RA. A uniquely specialised ear in a very early tetrapod. Nature 2003;425:65-9. doi:10.1038/nature01904.

Clement G, Ahlberg PE, Blieck A, Blom H, Clack JA, Poty E, Thorez J, Janvier P. Devonian tetrapod from western Europe. Nature 2004;427:412-3. doi:10.1038/427412a.

Coates MI. The Devonian tetrapod Acanthostega gunnari Jarvik: postcranial anatomy, basal tetrapod relationships and patterns of skeletal evolution. Trans R Soc Edinb Earth Sci. 1996;87:363-421.

Coates MI, Clack JA. Polydactyly in the earliest known tetrapod limbs. Nature 1990;347:66-9. doi:10.1038/347066a0.

Coates MI, Clack JA. Fish-like gills and breathing in the earliest known tetrapod. Nature 1991;352:234-6. doi:10.1038/352 234a0.

Coates MI, Clack JA. Romer's Gap - tetrapod origins and terrestriality. In: Arsenault M, Lelièvre H, Janvier P, editors. Studies on early vertebrates, vol. 17. Paris: Miguasha, Quebec, Bulletin du Muséum National d'histoire Naturelle; 1995. p. 373-88.

Coates M, Jeffery JE, Ruta M. Fins to limbs: what the fossils say. Evol Dev. 2002;4:390-401. doi:10.1046/j.1525-142X.2002. 02026.x.
Cressler WL. Plant paleoecology of the Late Devonian Red Hill locality north-central Pennsylvania, and Archaeopteris-dominated wetland plant community and early tetrapod site. In: Greb SF, DiMichele WA, editors. Wetlands through time. Geological Society of America special paper. Boulder, CO: Geological Society of America; 2006. p. 79-102.

Daeschler EB. Early tetrapod jaws from the Late Devonian of Pennsylvania, USA. J Paleontol. 2000;74:301-8. doi:10.1666/ 0022-3360(2000)074<0301:ETJFTL>2.0.CO;2.

Daeschler EB, Shubin NH, Thomson KS, Amaral WW. A Devonian tetrapod from North America. Science 1994;265:639-42. doi:10.1126/science.265.5172.639.

Daeschler EB, Shubin NH, Jenkins FA. A Devonian tetrapod-like fish and the evolution of the tetrapod body plan. Nature 2006;440:75763. doi:10.1038/nature04639.

Daeschler EB, Clack JA, Shubin NH. Late Devonian tetrapod remains from Red Hill Pennsylvania. Acta Zool; 2009 in press

Davis MC, Dahn RD, Shubin NH. An autopodial-like pattern of Hox expression in the fins of a basal actinopterygian fish. Nature 2007;447:473-7. doi:10.1038/nature05838.

Johanson Z, Joss J, Boisvert C, Ericsson R, Sutija M, Ahlberg PE. Fish fingers: digit homologues in sarcopterygian fish fins. J Exp Zool. 2007;308B:757-68. doi:10.1002jez.b.21197.

Lebedev OA. The first find of a Devonian tetrapod vertebrate in the USSR. Doklady Akademii Nauk SSSR. Palaeontology 1984;278: $1470-3$, in Russian.

Lebedev OI. A new tetrapod Jakobsonia livnensis from the Early Famennian (Devonian) of Russa and palaeoecological remarks on the Late Devonian tetrapod habitats. Acta Univ Latviensis Ser Earth Environ Sci. 2004;670:79-98.

Lebedev OA, Clack JA. New material of Devonian tetrapods from the Tula region, Russia. Palaeontology 1993;36:721-34.

Lebedev OA, Coates MI. The postcranial skeleton of the Devonian tetrapod Tulerpeton curtum Lebedev. Zool J Linn Soc. 1995;114:307-48. doi:10.1111/j.1096-3642.1995.tb00119.x.

Paton RL, Smithson TR, Clack JA. An amniote-like skeleton from the Early Carboniferous of Scotland. Nature 1999;398:508-13. doi:10.1038/19071.

Schultze HP, Arsenault M. The panderichthyid fish Elpistostege: a close relative of tetrapods? Palaeontology 1985;28:293-309.

Shubin NH, Daeschler EB, Coates MI. The early evolution of the tetrapod humerus. Science 2004;304:90-3. doi:10.1126/science.1094295.

Shubin NH, Daeschler EB, Jenkins FA. The pectoral fin of Tiktaalik rosae and the origin of the tetrapod limb. Nature 2006;440:76471. doi:10.1038/nature04637.

Vorobyeva EI. The shoulder girdle of Panderichthys rhombolepis (Gross) (Crossopterygii), Upper Devonian, Latvia. Geobios 1995;19:285-8. doi:10.1016/S0016-6995(95)80128-6.

Vorobyeva EI. Morphology of the humerus in the rhipidistian Crossopterygii and the origin of tetrapods. Paleontological J. 2000;34:632-41.

Vorobyeva EI, Schultze HP. Description and Systematics of panderichthyid fishes with comments on their relationship to tetrapods. In: Schultze H-P, Trueb L, editors. Origins of the higher groups of tetrapods. Ithaca: Comstock; 1991. p. 68-109.

Westoll TS. Ancestry of the tetrapods. Nature 1938;141:127-8. doi:10.1038/141127a0.

Zhu M, Ahlberg PE, Zhao W, Jia L. First Devonian tetrapod from Asia. Nature 2002;420:760-1. doi:10.1038/420760a. 